\title{
Alternativa social sustentável de captação da água da chuva em escola do campo na região da bacia hidrográfica do rio Jauru - MT
}

\author{
Sustainable social alternative for rainwater harvesting in a rural school in the Jauru river \\ watershed region - MT
}

Alternativa social sostenible para la captación de agua de lluvia en una escuela rural en la región de

la cuenca del río Jauru - MT

Luiz Cláudio Almeida Martins

ORCID: https://orcid.org/0000-0003-2967-2129

Universidade Estadual do Mato Grosso, Brasil

E-mail: claudinhomrtins_almeida@hotmail.com

Rosiane Alexsandra dos Santos Costa

ORCID: https://orcid.org/0000-0002-7203-3907

Universidade Estadual do Mato Grosso, Brasil

E-mail: rosianecosta22@gmail.com

Solange Aparecida Arrolho da Silva

ORCID: https://orcid.org/0000-0002-8038-1303

Universidade Estadual do Mato Grosso, Brasil

E-mail: solange.arrolho@unemat.br

\begin{abstract}
Resumo
Este artigo apresenta a importância da implantação de um reservatório cisterna para captação da água da chuva na escola do campo, sendo utilizada como opção viável para minimizar o problema relacionado à escassez de água. A escola situa-se na região da bacia hidrográfica do rio Jauru no Pantanal mato-grossense, as áreas degradadas com perdas de capacidade das nascentes, somados aos aspectos geológicos e geomorfológicos da região tem causado a escassez de água mesmo inserida na maior área úmida do planeta. Objetivou-se com este trabalho a caracterização da importância da implantação da cisterna para captação da água da chuva na Escola Estadual 12 de Outubro na região hidrográfica do rio Jauru-MT. O sistema apresentado é projeto desenvolvido na região de fronteira Brasil/Bolívia sendo uma alternativa para a captação da água da chuva. A cisterna foi implantada em uma escola do campo no Município de Cáceres-MT por meio do Projeto de construção de barraginhas e cisternas envolvendo os assentamentos, poder público e pesquisadores. Para o desenvolvimento do trabalho foi realizada uma revisão de literatura e aplicação de questionário semiestruturado online aos profissionais da educação sobre a percepção do uso da água captada da chuva e a importância da construção da cisterna na escola. O trabalho propõe diante da problemática de escassez de água na escola a importância da captação da água da chuva tendo em vista que a região sofre com a falta de água principalmente no período de estiagem.
\end{abstract}

Palavras-chave: Planejamento; Sustentabilidade; Uso consciente.

\begin{abstract}
This article presents the importance of implementing a cistern reservoir to capture rainwater in the rural school, being used as a viable option to minimize the problem related to water scarcity. The school is located in the region of the hydrographic basin of the Jauru river in the Pantanal of Mato Grosso, the degraded areas with loss of capacity of the springs, added to the geological and geomorphological aspects of the region have caused water scarcity even in the largest wetland of the planet. The objective of this work was to characterize the importance of installing a cistern for rainwater catchment at the State School 12 de Outubro in the hydrographic region of the Jauru River-MT. The system presented is a project developed in the Brazil/Bolivia border region and is an alternative for rainwater harvesting. The cistern was implemented in a rural school in the city of Cáceres-MT through the Project for the construction of dams and cisterns involving the settlements, public authorities and researchers. For the development of the work, a literature review was carried out and an online semi-structured questionnaire was applied to education professionals about the perception of the use of water collected from rain and the importance of building a cistern at school. The work proposes, given the problem of water scarcity at school, the importance of capturing rainwater, considering that the region suffers from a lack of water, especially during the dry season.
\end{abstract}

Keywords: Planning; Sustainability; Conscious use. 


\begin{abstract}
Resumen
Este artículo presenta la importancia de implementar un reservorio cisterna para captación de agua de lluvia en la escuela rural, siendo utilizado como una opción viable para minimizar el problema relacionado con la escasez de agua. La escuela está ubicada en la región de la cuenca hidrográfica del río Jauru en el Pantanal de Mato Grosso, las áreas degradadas con pérdida de capacidad de los manantiales, sumadas a los aspectos geológicos y geomorfológicos de la región han provocado escasez de agua incluso en el humedal más grande del planeta. El objetivo de este trabajo fue caracterizar la importancia de instalar una cisterna para captación de agua de lluvia en la Escuela Estatal 12 de Octubre en la región hidrográfica del río Jauru-MT. El sistema presentado es un proyecto desarrollado en la región fronteriza Brasil / Bolivia y es una alternativa para la captación de agua de lluvia. La cisterna se implementó en una escuela rural de la ciudad de Cáceres-MT a través del Proyecto de construcción de presas y cisternas que involucra a los asentamientos, autoridades públicas e investigadores. Para el desarrollo del trabajo se realizó una revisión de la literatura y se aplicó un cuestionario semiestructurado en línea a los profesionales de la educación sobre la percepción del uso del agua recolectada de lluvia y la importancia de construir un aljibe en la escuela. El trabajo plantea, ante el problema de la escasez de agua en la escuela, la importancia de captar el agua de lluvia, considerando que la región sufre de escasez de agua, especialmente durante la época seca.
\end{abstract}

Palabras clave: Planificación; Sustentabilidad; Uso consciente.

\title{
1. Introdução
}

A água é a substância mais abundante no planeta, embora disponível em diferentes quantidades e lugares, possui papel fundamental no ambiente e na vida humana, e nada a substitui, pois sem ela a vida não pode existir (Castrillon et al., 2017).

A disponibilidade de água potável ao consumo do ser humano pode ser considerada o principal fator à sobrevivência e à melhoria da qualidade de vida das populações rurais, sobretudo nas regiões áridas e semiáridas (Marchetto; Alves, 2021).

Desafios relacionados à disponibilidade de água ocorrem especialmente em regiões onde são constatadas as ocorrências de secas e de processos de degradação dos solos, ocasionados pela redução da cobertura vegetal, poluição do solo e da água, diminuindo a fertilidade natural do solo (Silva, 2020).

De acordo com Pimentel et al. (2021) em muitos casos, a qualidade da água da chuva pode superar a qualidade de águas superficiais e subterrâneas. Por não entrar em contato com o solo nem estar diretamente sujeita ao lançamento de poluentes de origem antropogênica, a água da chuva pode constituir uma fonte alternativa de água com qualidade razoável para diversos usos. Para que haja o reaproveitamento da água deve ser levada em conta toda técnica estará sempre condicionada à relação custo/benefício (Santos, 2020).

O armazenamento da água de chuva ocorre em reservatórios inferiores chamadas cisternas ou reservatórios superiores denominadas caixas d'água. De acordo com Marchetto e Alves (2021) uma cisterna é um depósito ou reservatório que serve para captar, armazenar e conservar a água, podendo ser da água potável, água da chuva ou água de reuso.

No caso das cisternas, estas podem ser enterradas ou não. Segundo Peters (2006), enterrar o reservatório faz com que a água permaneça com temperatura constante, não aquecendo muito durante o verão nem esfriando em demasia durante o inverno.

Neste contexto, pode-se afirmar que essas comunidades já sofrem com as consequências da escassez hídrica mesmo estando ao lado da maior área alagadiça do mundo, fator de preocupação que deve servir de reflexão sobre as atuais e futuras crises hídricas, uma vez que existem países e regiões que não irão ter recursos para a efetivação de tecnologias para a superação da falta de água como é o caso das comunidades vulneráveis (Ferreira, 2019).

Assim, Tomaz (2003) aponta a conscientização sobre a importância da economia de água como um dos principais fatores para mitigar o avanço desse grave problema. A partir dessa visão, o aproveitamento de água da chuva para consumo 
não potável é apontado como uma tecnologia de grande importância, utilizada em vários países com o intuito de conservar esse recurso natural.

Este trabalho trata da importância da captação da água da chuva armazenada em reservatório cisterna na Escola Estadual 12 de Outubro, localizada no município de Cáceres-MT, por meio da avaliação da viabilidade da implantação de um sistema com uso de técnica de captação de água de chuva, e da percepção dos profissionais da educação da escola em relação ao aproveitamento e consumo de água de cisterna na Escola. O trabalho se desenvolveu por meio de análise documental do projeto Plantando água ou barraginhas no Alto Pantanal de Cáceres-MT.

\section{Metodologia}

A realização da pesquisa contou com trabalhos de caráter bibliográfico embasando-se nas propostas metodológicas de Gil (2000) e Lakatos e Marconi (2007), que convergem no delineamento da pesquisa através de trabalhos publicados em livros, artigos científicos, monografias, dissertações e teses.

A Escola Estadual 12 de Outubro, localiza-se no município de Cáceres-MT, no projeto de assentamento Nova Esperança, na fronteira Brasil/Bolívia. Está inserida na bacia hidrográfica do Rio Jauru no Pantanal Mato-grossense (Figura $1)$.

Figura 1: Localização da Escola 12 de Outubro na região hidrográfica do Rio Jauru-MT.

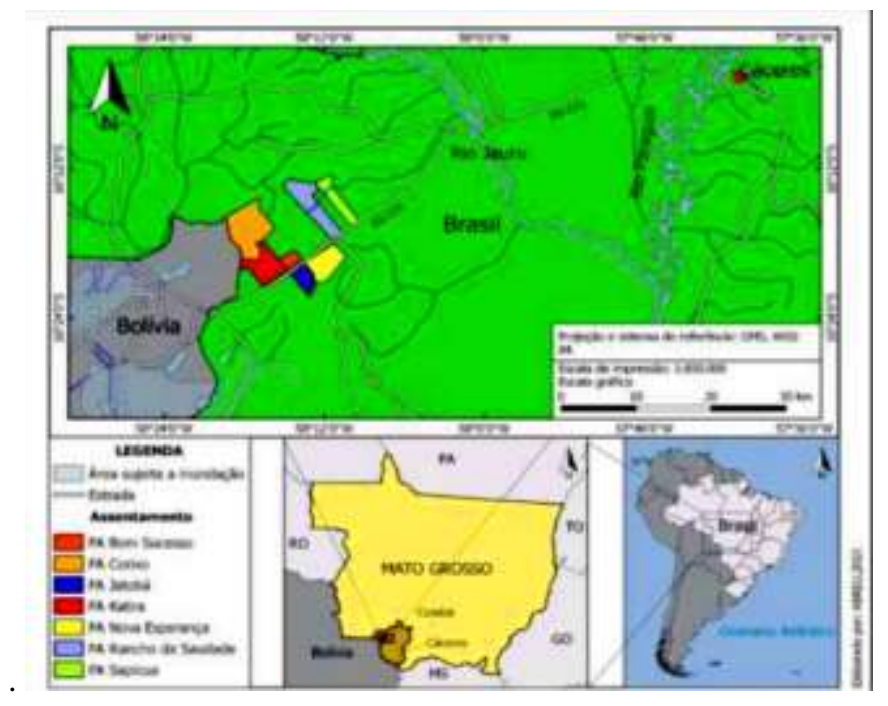

Fonte: Ferreira (2019).

A pesquisa se constitui a partir do levantamento de revisão de literatura publicada sobre o tema, por meio da revisão bibliográficas de livros, artigos científicos, teses, dissertações com base nas análises de fonte secundárias que abordam o tema de diferentes maneiras. Sendo adotada uma abordagem quali-qualitativa (Gunther, 2006). Realizou-se um estudo buscando opiniões, considerando a dinâmica existente entre a realidade e o sujeito, dos profissionais da educação procurando ouvi-los, explorando sua percepção, na realização das entrevistas e questionários, sistematizando os resultados em gráficos e tabelas, e os números obtidos para analisá-los.

No desenvolver dessa pesquisa foi aplicado questionário semiestruturado online na plataforma Google forms, aplicativo WhatsApp, composto por nove questões objetivas de caráter quali-quantitativo, para os 14 profissionais da educação entre eles, professores, técnico administrativo educacional e técnico de apoio educacional. 
Fez-se uma análise da percepção e do ponto de vista dos profissionais da educação a respeito da água captada da chuva armazenada em cisterna: sobre como eles fazem o uso; se a água captada da chuva em cisterna é de boa qualidade; e a quantidade é suficiente para suprir as necessidades básicas na escola.

Objetivou-se através do roteiro estruturado para a entrevista, saber a percepção dos profissionais da educação escolar sobre a importância da cisterna, do uso racional da água e os benefícios na captação da água da chuva.

\section{Resultados e Discussão}

\subsection{Precipitação na área da bacia hidrográfica do Rio Jauru}

O conhecimento da variação do volume mensal da precipitação pluviométrica média é de suma importância para qualificar e quantificar os efeitos ocasionados em áreas antrópicas, visando o adequado gerenciamento, planejamento e maximização do uso dos recursos hídricos disponíveis (Marcuzzo; Melati, 2016).

De acordo com dados obtidos no portal HIDROWEB, na estação pluviométrica Alto Jauru, referentes à série histórica de 1998 a 2018, localizada a latitude $15^{\circ} 26^{\prime} 24.00^{\prime \prime S}$ e $58^{\circ} 35^{\prime} 16.08^{\prime \prime} \mathrm{W}$, a altitude de $235 \mathrm{~m}$, a precipitação média anual foi de $1473 \mathrm{~mm}$, sendo 2010 o ano mais seco, com 1126mm, e 2017, ao ano mais chuvoso, com 1948mm. Os anos de 2000 e 2013 não constam devido à ausência dos dados em alguns meses desses períodos, não sendo possível contabilizar a precipitação anual total.

A figura 2 apresenta o histograma de precipitações anuais na estação pluviométrica do rio Jauru compreendido entre os anos de 1999 a 2018, onde pode-se observar que as maiores quedas nas precipitações aconteceram nos anos 2005 a 2007, sofrendo uma pequena elevação nos anos posteriores alcançando seu pico no ano 2017, vindo a sofrer novamente uma queda significativa no ano posterior.

Figura 2: Histograma de precipitações anuais totais na estação pluviométrica do Alto Jauru -1999 a 2018.

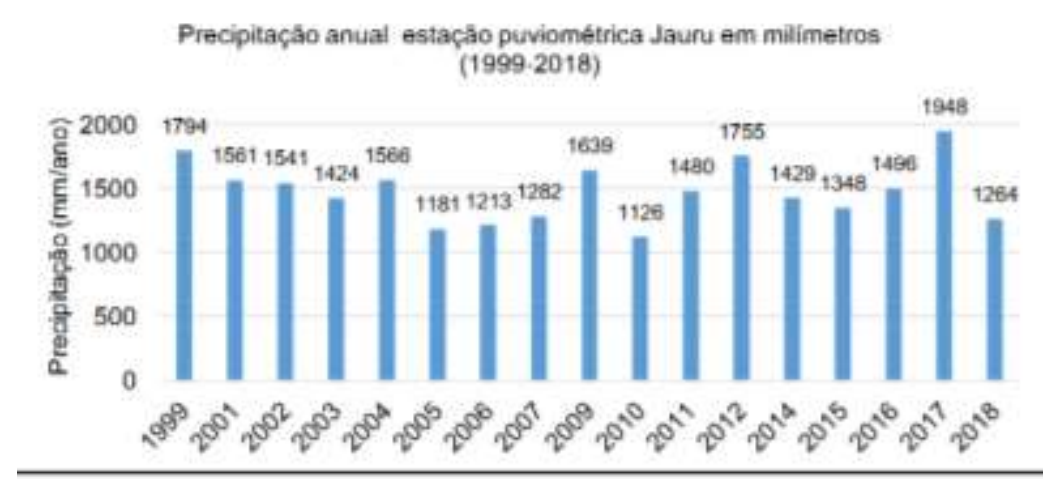

Fonte: Vollmer (2019).

O período não chuvoso no Pantanal é de seis meses e a precipitação anual média da região é de $1.200 \mathrm{~mm}$, considerada acima da média nacional. Entretanto, na região de Cáceres, principalmente na região fronteiriça com a Bolívia (a Oeste), as fontes de água na região, como o rio Jauru e rio Paraguai são distantes, além da precipitação que é mais escassa ainda, devido à geologia do local, as águas subterrâneas nesta região são de difícil acesso, com captação desfavorecida (Curi, 2011).

Segundo Curi (2011) as fontes de água, como o rio Jauru estão distante cerca de $25 \mathrm{~km}$, as águas dos corixos são contaminadas e a água subterrânea nesta região é de difícil captação pela questão geológica que não favorece acarretando baixa qualidade e altos custos para famílias de baixa renda. 
A alternância de anos extremamente chuvosos com anos de poucas chuvas até mesmo escassas sobre o pantanal norte de Mato Grosso, configura-se como um sério problema para as famílias que ocupam esse espaço, onde a irregularidade das chuvas interfere diretamente na vida e na dinâmica social e econômica do ecossistema pantaneiro (Silva, 2020).

\subsection{Captação da água da chuva em cisterna na escola do campo}

Neste contexto, a captação da água de chuva torna-se uma alternativa viável que somada a outras políticas públicas, contribuiu com o desenvolvimento sustentável da região, sendo a construção de cisternas uma destas alternativas com melhor relação custo-benefício (Alves, 2016). Segundo Silva (2020), este é um sistema de aproveitamento da água da chuva de baixo custo que serve para armazenar água para usos no ambiente doméstico, sendo considerado uma das melhores e mais eficazes alternativas para economia de água e estão disponíveis em vários modelos, formatos e tamanhos, podendo ser instaladas em casas, escolas e indústrias.

Na região hidrográfica do rio Jauru no município de Cáceres-MT, região de fronteira Brasil/Bolívia existe sete assentamentos da Reforma Agrária, duas escolas do campo, sendo uma municipal e outra estadual com cerca de aproximadamente 300 alunos.

Os reservatórios existentes na escola, objeto de estudo, fazem parte apenas de uma das seis ações que integram o programa de acesso à água da chuva e educação ambiental que foi desenvolvido pelo INCRA na região da fronteira com a Bolívia (Ferreira, 2019).

A água é captada por meio de calhas instaladas nos telhados das escolas e o armazenamento é feito em reservatórios lonados doados com geomembrana de PVC 0,8mm PEAD e cobertos. A Escola Estadual 12 de Outubro recebeu uma cisterna de 125 mil litros (Figura 3).

Figura 3: Implantação de cisterna na escola estadual 12 de outubro.
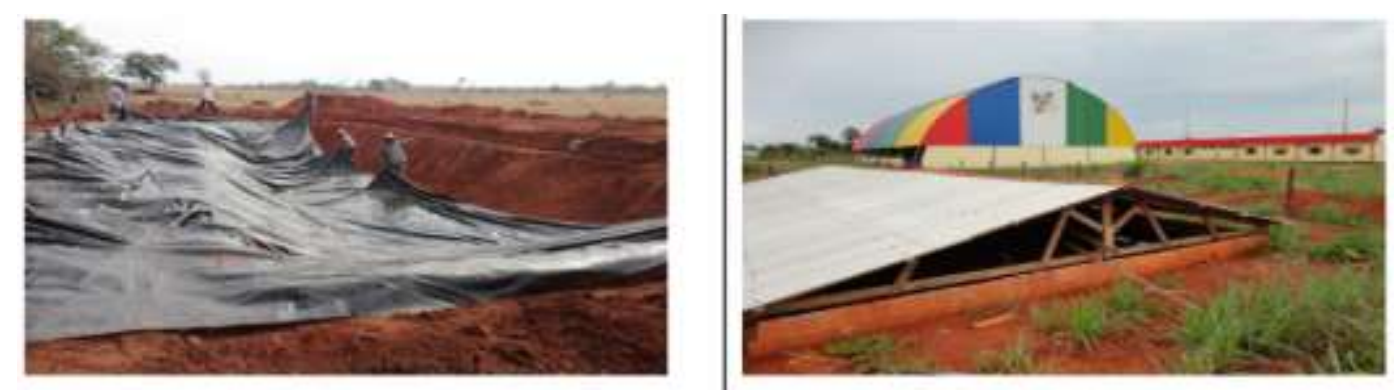

Fonte: Curi (2011).

A captação de água de chuva através de telhados e outras superfícies e seu armazenamento em cisternas, é uma técnica de baixo custo e fácil implantação e operação que pode ser utilizada, não apenas para solucionar problemas de escassez esporádica de água, como para propiciar o consumo racional da mesma, através da utilização direta de um recurso antes desperdiçado (Gnoatto, 2018).

Apesar de estar localizada em região pantaneira, a área estudada é carente em recursos hídricos, a indisponibilidade de água superficial, assim como a acessibilidade às águas subterrâneas é um dos principais desafios em se obter esse recurso natural precioso (Silva, 2020). Podendo-se afirmar, de acordo com Ferreira (2019), que essas comunidades já sofrem com as consequências da escassez hídrica mesmo estando ao lado da maior área alagadiça do mundo, fator de preocupação que deve servir de reflexão sobre as atuais e futuras crises hídricas, uma vez que existem países e regiões que não irão ter 
recursos para a efetivação de tecnologias para a superação da falta de água como é o caso das comunidades vulneráveis (Ferreira, 2019).

A cisterna presente na escola estadual representa uma oportunidade de disseminar as práticas sustentáveis de aproveitamento e uso da água, recurso esse imprescindível para a sobrevivência humana, aos membros da comunidade escolar e a sociedade como um todo.

\subsection{Concepção dos profissionais da educação sobre a situação hídrica na Escola e a utilização da água captada da chuva em reservatório cisterna.}

O principal desafio para a gestão da água na comunidade do assentamento é provê-la na quantidade necessária que atenda à demanda familiar, sem desperdícios, com qualidade compatível com seus usos, em locais e condições economicamente viáveis e de forma sustentável (Silva, 2020).

Fez se diversos questionamentos aos profissionais da educação referente aos benefícios que a construção do reservatório cisterna pode gerar para a escola. A pergunta foi aberta e descritiva, as respostas foram variadas, principalmente com relação a utilização da água, mas a mais frequente foi que a água da chuva armazenada em cisterna é utilizada principalmente para manutenção estrutural da escola.

A cisterna além de contribuir com o meio ambiente, também tem a oportunidade de ser um espaço permanente de aprendizagem e transformação com base no diálogo e na cooperação. Tornou a escola com um desafio, educar para a sustentabilidade ao mesmo tempo em que se transforma em um espaço educador sustentável, esse desafio repercute na sociedade ao mesmo tempo em que demonstra que é possível construir espaços que mantenham uma relação equilibrada com o meio ambiente, diminuindo o impacto causado pela ação do homem (Gnoatto, 2018).

Para reforçar essa interpretação, foi perguntado a eles, se a água captada pela chuva e armazenada em reservatório cisterna dispõe de uma qualidade e quantidade adequada para a utilização na escola e para as necessidades humanas. De acordo com as respostas, reconhece-se que há existência de diversos problemas relacionada no tocante à qualidade da água captada da chuva e armazenada em cisterna.

As seguintes justificativas foram apresentadas: "água é impróprio para o consumo", "utilizada para as necessidades da limpeza, hortas, plantas na escola", "água sem tratamento e apenas um profissional teve a resposta sim que a água captada da chuva e armazenada na cisterna dispõe de qualidade e quantidade adequada para a utilização na escola e para o consumo".

Os profissionais também foram questionados sobre qual é o principal fator de escassez de água na escola, e em resposta afirmam ser "lugar difícil de acesso à água", "na região da escola não água no lençol freático", "lugar muito seco", "não tem mina de água", "poços artesianos não atendem à demanda na região", "o solo da região é um fator de restrição de água". Apesar das diferenças das respostas, a maioria acredita que a escassez de água na região tem a ver com o solo da região que interfere diretamente no lençol freático, mesmo a região estar inserido na região do Pantanal.

Foi perguntado sobre a percepção de cada um em relação a reduzir a escassez de água na escola. Foram observadas várias respostas associadas ao uso consciente da água, importância da natureza, econômica da água, reuso da água, pesquisa e prática nos resultados.

Foi questionado quais atividades despertam interesses para as aulas práticas com a implantação da cisterna na escola. As opiniões relatadas apontam para procedimentos de uma boa conduta, e que estejam voltadas para uma educação ambiental que contemple a aquisição de hábitos, valores, mudanças de atitudes e comportamentos, voltados principalmente para o fim do desperdício e uso consciente da água, tanto no interior da escola.

Por conta da falta de água principalmente no período de estiagem a escola quase foi fechada devido à falta de água para ser utilizadas nas necessidades básicas. A cisterna garantiu o acesso à água, proporcionando a água em períodos de 
estiagem, mostrando ser muito eficiente como sistema de gestão da água para escola localizada no campo, promovendo a sustentabilidade do homem no campo.

A figura 4 demostra que o item horta foi citado por maioria dos profissionais da educação da escola, em seguida as atividades voltadas a consciência ambiental que despertam interesses nas aulas práticas, utilização da água para regar o jardim e aula campo.

Figura 4: Itens apontados pelos professores sobre atividades que despertam interesse nas aulas práticas com a captação de água de chuva.

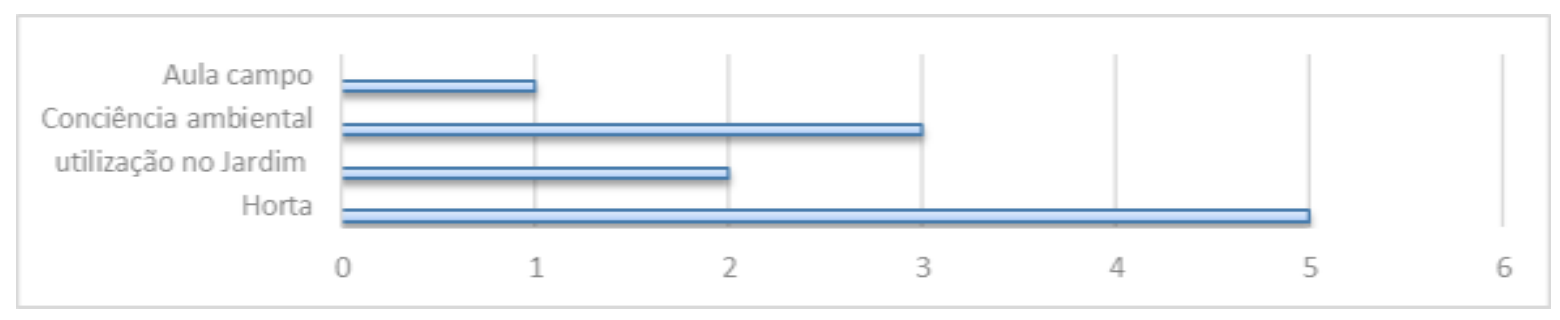

Fonte: Autores (2021).

Analisando ainda a Figura 4, o projeto horta implantada na escola vai além da utilização nas refeições dos alunos como também um de interesse da aula prática na horta escolar. A abordagem prática desse elemento se dá por meio de atividades envolvendo cultivo de hortaliças, levando a produção e aproveitamento de legumes no âmbito escolar, como forma de melhoria da alimentação consumida na Escola. A horta é um laboratório vivo acessível a diversas práticas didáticas. A sua inserção propicia uma serie de benefícios à comunidade escolar, como debater conteúdos pertinentes à educação ambiental e a saúde por meio dos vários elementos.

O que se produz na horta é um alimento limpo, saudável, derivado de um sistema de cultivo que analisa as leis da natureza e todo o manejo agrícola está baseado no respeito ao meio ambiente, na conservação dos recursos naturais e no acréscimo da biodiversidade (Ribeiro, 2018).

Foi perguntado aos profissionais da educação se o professor fosse trabalhar com a educação ambiental e os benefícios da captação da água da chuva armazenada em cisterna dentro da sua disciplina, qual abordagem faria. Na figura 5 apresenta-se a abordagem sobre a educação ambiental e os benefícios da captação da água da cisterna em sala de aula.

Figura 5: Abordagem sobre educação ambiental e benefícios da captação da água da cisterna em sala de aula.

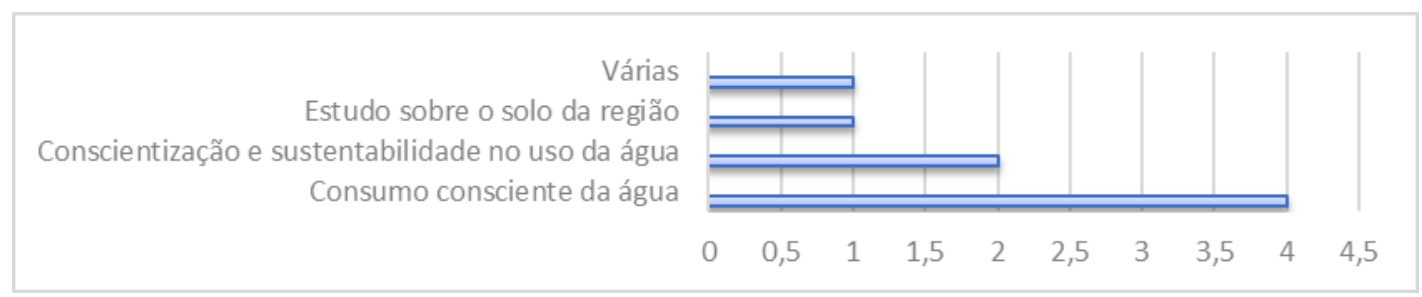

Fonte: Autores (2021).

Diante das respostas dos profissionais da educação fica evidente que a utilização da água da chuva armazenada na cisterna implantada soluciona em parte a escassez de água na escola nos períodos mais críticos que região passa na época da estiagem. Falaram ainda que é importante conscientizar toda a comunidade escolar sobre o benefício da construção de um sistema de captação de água de chuva na escola, pois com a sua implantação permitiu a inclusão da dimensão ambiental no currículo escolar. 
A educação ambiental é compreendida como ação educativa que contribui com a formação de cidadão nas mudanças de atitudes, na formação crítica e na conservação ambiental. De acordo com Frade, Pozza e Borém (2010) Educação Ambiental empregada nas escolas, por exemplo, deve possuir uma visão crítica e, para tanto, é necessário que sejam discutidas as degradações ambientais de maneira integrada em todos os campos do saber. Para Rodrigues (2019), a mesma é compreendida como toda e qualquer ação educativa que passe a contribuir para a formação de um cidadão mais consciente em relação à conservação do meio ambiente.

Apontamos sobre a importância da reflexão e se discutir esse tema com os profissionais da educação, comunidade escolar, os assentados, para entendermos as ideias e sugestões sobre o consumo da água de maneira sustentável e como dever ser aproveitado de formar racional evitando o desperdício. No contexto pedagógico as iniciativas da escola em desenvolver projetos que abrange todos os envolvidos de modo geral leva a conscientizar os alunos da importância da captação da água da chuva, a importância da implantação da cisterna de modo que possa evitar os problemas no período da estiagem. A iniciativa deve ser considerada uma sugestão para que seja difundida a partir de políticas públicas. Na sala de aula ou fora dela, os alunos devem participar e aprender iniciativas de maneira que percebam a importância de cuidar e conservar tudo que faz parte do meio ambiente.

\section{Considerações Finais}

Ao analisar os resultados obtidos com esta pesquisa junto aos profissionais da educação da Escola Estadual 12 de Outubro situada no assentamento Nova Esperança no município de Cáceres-MT, verifica a importância da implantação da cisterna e o valor da água tem para essa escola desenvolver o seu trabalho.

Diante desses resultados percebe-se que, de modo geral, parte dos profissionais da educação que respondeu o questionário aponta uma grande satisfação com a água utilizada na Escola e mostraram ter a consciência da relevância da construção de cisterna no armazenamento da água para ser utilizada no período de estiagem, com a percepção de que essa água captada da chuva e armazenada na cisterna aumenta a oferta de água assegurando-a o consumo da escola, contribui assim, para a melhoria da qualidade de vida.

\section{Referências}

Alves, M. F. (2016). Avaliação de Sistema de Cisternas Para Captação de Água de Chuva Instalados em Comunidades Rurais de Mato Grosso -Brasil. E\&S -Engineering and Science. 10.18607/ES20165049

Castrillon, S. I., PuhL, J. I., Morais, F. F. \& Lopes, A. E. T. M. (2017) Escassez Hídrica e Restauração Ecológica no Pantanal: Recuperação das nascentes e fragmentos de mata ciliar do córrego no Assentamento Laranjeira I e mobilização para conservação dos recursos hídricos no Pantanal Mato-grossense. (pp 43-56). Carlini \& Caniato Editorial.

CONAMA. Conselho Nacional do Meio Ambiente. Resolução CONAMA 357, Ministério do Meio Ambiente. http://www2.mma.gov.br.

Curi, S., Marchetto, M. \& Okada, A. S. (2011). Projeto plantando água ou barraginhas no Alto Pantanal de Cáceres. p.3-8

Ferreira, N. (2019). Água, mulheres do campo e saúde no contexto da escassez hídrica: Estudo de caso em assentamentos rurais no município de Cáceres-MT. Trabalho de conclusão de mestrado. Universidade do Estado de Mato Grosso. Programa de Pós-graduação em Ciências Ambientais. Cáceres-MT.

Frade. E. das G, Pozza, A. A. A, Borém, R. A. T. (2010). Educação Ambiental na diversidade: Guia de estudos. UFLA. http://revistaea.org/artigo.php?idartigo=1445

Gnoatto, A. (2018). Projeto cisterna: Um processo educativo de construção e uso racional da água. (pp.2-5) Congresso técnico cientifico de engenharia e da agronomia. Brasil. https://www.confea.org.br/sites/default/files/antigos/contecc2018/agronomia/189_pcupedceurda.pdf

Gerhardt, T.E. \& Silveira, D.T. (2009). Métodos de pesquisa. UFRGS. 120 p

Günther, H. (2006). Pesquisa qualitativa versus pesquisa quantitativa: esta é a questão? Revista Psicologia: teoria e pesquisa. Brasília: Editora da UnB.

Gil. A. C.(2000). Métodos e técnicas de pesquisa social. Atlas.

Lakatos, E. M. \& Marconi, M. A. (2007). Técnicas de pesquisa. (3a ed.), Atlas. 
Research, Society and Development, v. 10, n. 9, e50810918257, 2021

(CC BY 4.0) | ISSN 2525-3409 | DOI: http://dx.doi.org/10.33448/rsd-v10i9.18257

Marchetto, M \& Alves, M.A. (2021). Tecnologias sociais em comunidades isoladas. Referencial de escolha de soluções para saneamento rural (pp. 56-71) Gráfica e Editora Cuiabá.

Marcuzzo, F. F. N \& Melati, M. D. (2016). Caracterização de precipitação pluviométrico mensal nas sub-bacias pertencentes a bacias do rio Uruguai. XXIII Simpósio de recursos hídricos do Nordeste. https://rigeo.cprm.gov.br/handle/doc/17183

Peters, M. R. (2006). Potencialidade de uso de fontes alternativas de água para fins não potáveis em uma unidade residencial. 2006. 109f. Dissertação (Mestrado em Engenharia Ambiental) - UFSC, https://repositorio.ufsc.br/bitstream/handle/123456789/88951/232845.pdf?sequence=1

Ribeiro, L. L.G. (2015). Direito à educação na diversidade: A prática do bullying no ambiente da escola pública e a responsabilidade do Estado. Revista de Direito Administrativo Contemporâneo, 21, 145-166.

Ribeiro, P. (2018). Horta escolar como recurso didático para a reeducação alimentar e nutricional. UFSC. Florianópolis https://repositorio.ufsc.br/handle/123456789/191018

Rodrigues, A. P. (2019). A Agenda 2030: Transparência e opacidade dos/nos discursos para a globalização. 2019. 155f. Tese (Doutorado). Pós-Graduação em Ciências da Linguagem da Universidade do Vale do Sapucaí, Pouso Alegre.

Silva, M. C. A. (2020). Impactos das barraginhas: Uma tecnologia social no cotidiano de família do assentamento rancho da saudade no município de Cáceres-MT. Trabalho de conclusão de mestrado. Universidade do Estado de Mato Grosso. Mestrado Profissional em Gestão e Regulação de Recursos Hídricos. Cuiabá.

Santos, C. F. (2020). Aproveitamento de água de chuva para fins potáveis numa escola pública no interior do município de Campo Formoso (BA). Revista Monografia Ambiental Santa Maria, v.19, 9.

Tomaz, P. (2003). Aproveitamento de água de chuva. Editora Navegar.

Volmmer, F. F., Gonçalves, K. E. C., Martins, L. C. A., Batista, C. A. \& Gonçalves, T. F. A. (2019). Caracterização hidrológica da bacia hidrográfica do rio Jauru-MT. Brasil. I seminário internacional de Ciências Ambientais da Unemat. Cáceres-MT. 